\title{
DIAGNÓSTICO NUTRICIONAL E DE SAÚDE DE CRIANÇAS INSTITUCIONALIZADAS - CRECHE ELISIO TEIXEIRA LEITE, PERUS, SP, 1993*
}

\author{
Marina Paula Bertho** \\ Sara de Lima Estima** \\ Elizabeth Fujimori*** \\ Ida Maria Vianna de Oliveira ${ }^{\star \star \star}$
}

BERTHO. M.P et al. Diagnóstico nutricional e de saúde em crianças institucionalizadas . Creche Elisio Teixeira Leite. Perus, SP. 1993. Rev. Esc. Enf. USP. v.29. n.2. p. 141.57 ago. 1995

Como parte de um estudo sobre condições de saúde de crianças institucionalizadas, avaliou-se através de indicadores antropométricos (peso e altura) o estado nutricional de uma amostra de 111 crianças matriculadas numa creche Municipal. Perus - São Paulo. Também verificou-se a incidência de morbidades e a procedencia das crianças desnutridas. Utilizando os critérios diagnósticos da classificação de Gomez obteve-se 50,0\% de desnutridos, apresentando $23,4 \%$ de formas leves, $22,3 \%$ de moderadas e $4,3 \%$ de severas. Considerando os resultados obtidos através da classificação sugerida por Waterlow, prevaleceu a desnutrição crônica atual (30.8\%). A distribuição etária das crianças desnutridas mostrou maior incidência na faixa de 12.48 meses. Em relação ao perfil de morbidades as doenças infecciosas gastro-intestinais e respiratórias mostraram maior incidencia. Tanto o diagnóstico antropométrico como o de morbidade refletiram a baixa qualidade de vida predominante nas micro-áreas. sobretudo naquelas de procedencia das crianças desnutridas (micro-áreas 4 e 5). Os resultados indicam pois, como medida de caráter imediato um melhor acompanhamento da evolução pondo-estatural e do consumo alimentar, além de maior cobertura da faixa de menores de 24 meses, com o objetivo de deteç̧ão precoce e maior probabilidade de recuperação de "deficits" de peso e mesmo de estatura.

INITERMOS: Saúde da criança. Diagnóstico antropométrico. Pré-escolares. Creches.

\footnotetext{
* Projeto de intervenção das disciplinas Enfermagem Preventiva e Comunitária e Nutriçào Aplicada à Enfermagem.

** Alunas do 7 "semestre do Curso de Graduação em Enfermagem e Obstetrícia da Universidade de Sao Paulo.

*** Professor Doutor - Departamento de Enferinagem em Saúde Coletiva - Escola de Enferma gem da Universidade de Såo Paulo.
} 


\section{INTRODUÇÃO}

No Brasil. dados de consumo alimentar têm demonstrado que o desgaste de energia da classe trabalhadora é maior que a reposição e está associado a baixa remuneraçoo'. Assim se justifica a maior prevalência de desnutrição, sobretudo calorico-proteica entre a classe trabalhadora. Essa deficiência nutricional constitui-se em uma das principais causas de morbi-mortalidade infantil no Brasil e em outros países considerados técnica e economicamente subdesenvolvidos e caracterizados pela pobreza, demonstrada por uma baixa renda "per capita" e familiar".

Saloe-se que a melhoria das condições nutricionais dessa população está associada a modificações no padrão de vida, sobretudo dependentes de um aumento e uma melhor distribuição de renda ${ }^{4}$. Desta forma reconhece-se que a soluça do problema exige profundas mudanças estruturais na organização social. política e econômica do país ${ }^{1.4}$.

No entanto, a gravidade do problema e as dificuldades de implementação de medidas resolutivas têm justificado, no Brasil, a proliferação de medidas interventivas imediatas voltadas aos grupos de risco, no qual se incluem as crianças ${ }^{4}$. Essas medidas se explicitam nos inúmeros programas governamentais voltados para a alimentação e nutrição e são coerentes com o modelo de desenvolvimento sócio-econômico adotado ${ }^{14}$. Apesar do notável crescimento no número desses programas de suplementação, sua validade tem sido questionada ${ }^{3.415}$. Considera-se quo não têm contribuído de forma significativa para a melhoria das condiçoes nut ricionais das crianças brasileiras e que sua eficácia pode ter sido aletada negativamente não so pela descontinuidade e baixa cobertura ${ }^{3.1}$. mas lambem pela reduzida freqüencia de criancas mais polores as creches ${ }^{15}$. Lintretanto, alguns estudos têm evidenciado que mesmo as crianças que freqüentam creches ou instituiçoes similares em tempo inte. gral. podem permanecer som alcançar seus requisitos nutricionats e portanto permanecer desnutridas ${ }^{19}$. Wiste fato pode ser decorrente da dificuldade das instituiçoes em manter a disponililidade de alimentos, o padrão alimentar planejado ou mesmo um padrão alimentar adequado as necessidades das crianças. llá que se considerar, ainda. que nos grupos populacionais de baixa renda, pode não haver suplementação alimentar significativa no período em que a criança permanece no domicílio. $\Lambda \mathrm{l} e \mathrm{~m}$ disso, a disponibilidade de alimentos nas creches pode não estar necessariamente associada a uma ingestão adequada. pois muitas vezes as condições de desnutrição associadas a parasitoses crônicas e outras infeceões acarretam anorexia em diferentes graus. interferindo no consumo alimentar.

E. pois. imperativa a implantação e/ou manutencão de um sistema de vigilancia alimentar e nutricional que seja aderente as propostas de assis- 
tência à saúde desse grupo populacional. () diagnóstico das condições de nu. trição e saúde prevalentes entre crianças institucionalizadas é um dos recursos disponíveis na implementação dessa vigilância e constitui o propósito deste estudo.

\section{OBJETIVOS}

()s objetivos específicos deste estudo foram:

- avaliar através de diagnóstico antropométrico, o estado nutricional das crianças matriculadas em uma creche selecionada:

- caracterizar o perfil de morbidade dessas crianças:

- conhecer a procedencia das crianças. sobretudo das consideradas desnutridas.

\section{METODOLOGIA}

\section{População estudada}

Foi constituída por 111 crianças de 5 a 60 meses de idade matriculadas na creche Municipal "Elísio Teixeira Leite", uma das 35 instituiçoes Municipais do Distrito de Perus, região oeste do Município de São Paulo.

$\Lambda$ cobertura do exame antropometrico. realizado entre 24 de março e 27 de abril de 1993 . Foi de $85 \%$ totalizando 94 crianças, sendo $48.9 \%$ do sexo masculino o $51.1 \%$ do sexo feminino. Não foram incluídos na amostra os faltosos em mais de 2 períodos de coleta de dados (17 crianças).

\section{Caracterização geral da creche}

() distrito do Perus como outros distritos do Município de São Paaulo. estáa setorizado em regiões. que compreendem um ou mais bairros com condi. çōes socio-econômicas similares. denominados de microáreas.

$\Lambda$ creche "Llísio Teixeira Leeite" o uma das creches de administração direta sob supervisão da SURBES (Supervisão Regional do Bem Lstar Social). e está localizada na microárea 6. bairro (C) (IIAB-Pirituba.

Foram levantados. atraves de entrevista com diferentes profissionais da creche. os seguintes dados: 
- $\quad$ horário de funcionamento - Apenas em dias úteis, das 7 às 19 horas.

- $\quad$ selecão e matrícula - Os pré-requisitos considerados no processo de seleção eram: exercício, pela mãe, de atividade remunerada fora do domicílio; renda familiar inferior a 3 salários mínimos; moradia em casa alugada ou cedida, necessidade de remuneração de terceiros para o cuidado da criança ou permanência desta sozinha na residência e carteira de vacinação atualizada. Também era usual realizar uma entrevista com o responsável pela criança para levantamento de dados psicopedagogicos e de saúde durante a matricula.

- distribuicão das crianças - $\Lambda$ s crianças eram normalmente distribuídas, em função da idade, em diferentes módulos, conforme QUADRO 1.

\section{QUADRO 1:DISTRIBUIÇÃO DAS CRIANÇAS E FUNCIONÁRIOS NOS DIFERENTES MÓDULOS}

\begin{tabular}{|c|c|c|c|c|c|}
\hline \multirow[t]{2}{*}{ MOULO } & \multirow[t]{2}{*}{ PANAETARLI') } & \multicolumn{2}{|c|}{ NÜrero } & \multicolumn{2}{|c|}{ RUZAO AOIE-CRIANÇA } \\
\hline & & CRIANEAS & $A \mathrm{Als}^{(2)}$ & PROPOSTA & RENL \\
\hline 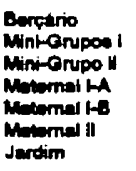 & 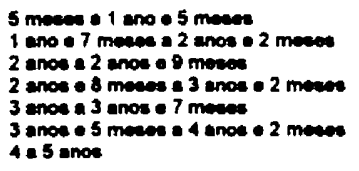 & $\begin{array}{l}17 \\
19 \\
12 \\
11 \\
19 \\
18 \\
18\end{array}$ & $\begin{array}{l}2 \\
2 \\
2 \\
1 \\
1 \\
1 \\
1\end{array}$ & $\begin{array}{l}1: 6: 1: 8 \\
1: 10 \\
1: 18 \\
1: 16 \\
1: 18 \\
1: 16 \\
1: 20\end{array}$ & $\begin{array}{l}1: 8,5 \\
1: 8 \\
1: 6 \\
1: 11 \\
1: 19 \\
1: 18 \\
1: 18\end{array}$ \\
\hline TOTAL & & 111 & 10 & & \\
\hline
\end{tabular}

1-a creche não utilizava a faixa etária recomendada pela SURBES 2-total de $\Lambda$ uxiliares de Desenvolvimento Infantil (ADI) por periodo 3-proposta de relação ADIs-criança de OLIVEIRA, Z.M.R.; FERREIRA, M.C.R. ${ }^{13}$ 


\section{Avaliação antropométrica e critérios diagnósticos de classificação da desnutrição}

Utilizou-se, neste trabalho, indicadores antropomótricos, por serem considerados instrumentos de grande sensibilidade e especificidade no diagnóstico da desnutrição, e também pela facilidade e baixo custo de sua operacionalizacãa ${ }^{10.11}$. () instrumento utilizado para registro dos dados antropométricos coletados continha dados de identificação, procedência, idade, data de matrícula na creche, data da última verificação de peso e altura além dos dados de peso e altura atuais e de classificação nutricional. $\Lambda$ s medidas do peso e da altura foram tomadas, de acordo com o recomendado pela Norma T'écnica 32/85 da Secretaria de Estado da Saúde do Estado de São Paulo ${ }^{16}$. através de balança com haste e cesto metálico e antropômetro de madeira (para crianças menores de 2 anos), e de balança antropometrica (tipo adulto) e fita métrica fixada longitudinalmente (para crianças maiores de 2 anos). Para a avaliação da adequação do peso e altura foram utilizadas as curvas de evolução pondo-estatural propostas, tambem, pela Secretaria de Estado da Saúde do Estado de São Paulo ${ }^{16}$. a partir de dados antropom etricos levantados por M $\triangle R Q U E S$ et $\mathrm{al}^{8}$, tendo-se considerado desnutridas as crianças com peso e/ou estatura abaixo do percentil 25 . $\Lambda$ classificação da desnutrição foi efetuada segundo ( a classificação proposta por WATERI () $\mathrm{W}^{18}$, com o objetivo de identificar, não apenas formas agudas mas crônicas de desnutrição.

\section{Caracterização do perfil de morbidades}

()s dados sobre as principais doenças que acometeram as crianças. no período de janeiro a abril de 1993, foram coletados atraves de consulta a prontuários e livros diários de intercorrências de cada módulo. $\Lambda$ s enfermidades foram agrupadas de acordo com a classificação utilizada na própria ereche.

\section{Levantamento da área de procedência das crianças desnutridas}

Através dos dados de endereco, obtidos dos prontuários das crianças. foi localizada a micróarea de procedência das crianças classificadas como desnutridas pelo critério de diagnóstico de ( $\$() \mathrm{M} \mathrm{E} \% Z^{6}$. 


\section{RESULTADOS E DISCUSSÃo}

\section{Estado nutricional}

$\mathrm{Na}$ Tabela 1 são apresentados os resultados obtidos pela avaliação de peso e altura atraves de percentis, que demonstram ser ligeiramente maior a porcentagem de desnutridos quando se considera o peso em relação a idade (54.3\%) do que a altura em relação a idade (53,2\%). Estes resultados superam significativamente os referidos pelo Estudo Nacional de Despesa Familiar - ENDEF 1974-1975) e sobretudo pela Pesquisa Nacional de Saúde e Nutrição - PNSN $1989^{7}$ para o Brasil $(18,4 \%$ e $7.1 \%$. respectivamente) e ate mesmo para a região Nordeste (27.0\% e $12.8 \%$. respectivamente). Se aproximam. porém, da elevada prevalência observada para a desnutrição crônica entre crianças brasileiras classificadas no quartil mais baixo de renda. que supera os $30 \%{ }^{3.5}$.

$\Lambda$ ocorrência de "deficit" ponderal se apresenta concentrada na faixa de 12 a 48 meses ( $78.5 \%$ dos desnut,ridos), assim como a ocorrencia de "deficit" estatural (72,0\% dos desnutridos). ()s resultados tambem mostram uma incidência de $11,8 \%$ ("deficit" de peso) e $20,0 \%$ ("deficit" de altura) em crianças de 48 a 60 meses. Esta distriluuição etária da desnutrição aponta para uma relativa proteção da faixa de idade correspondente ao primeiro ano de vida. tambem olservada por MONTEIRO"'. () autor sugere, entre outros determinantes dessa menor vulnerabilidade, a presença do aleitamento da suplementação alimentar e de maior cobertura do acompanhamento médico e melhor controle de diarrétas.

$\Lambda$ aplicação da classificação de Gomez pretendeu mostrar a gravidade da desnutrição e os resultados estão apresentados na Tahela 2. Para o total da amostra a ocorrencia de desnutrição foi de $50.0 \%$. correspondendo as formas leves $23.4 \%$ (grau J). As formas moderadas (grau II) atingiram $22,3 \%$ das crianças sendo que apenas $4.3 \%$ apresentaram formas severas de desnutrição (grau III). 


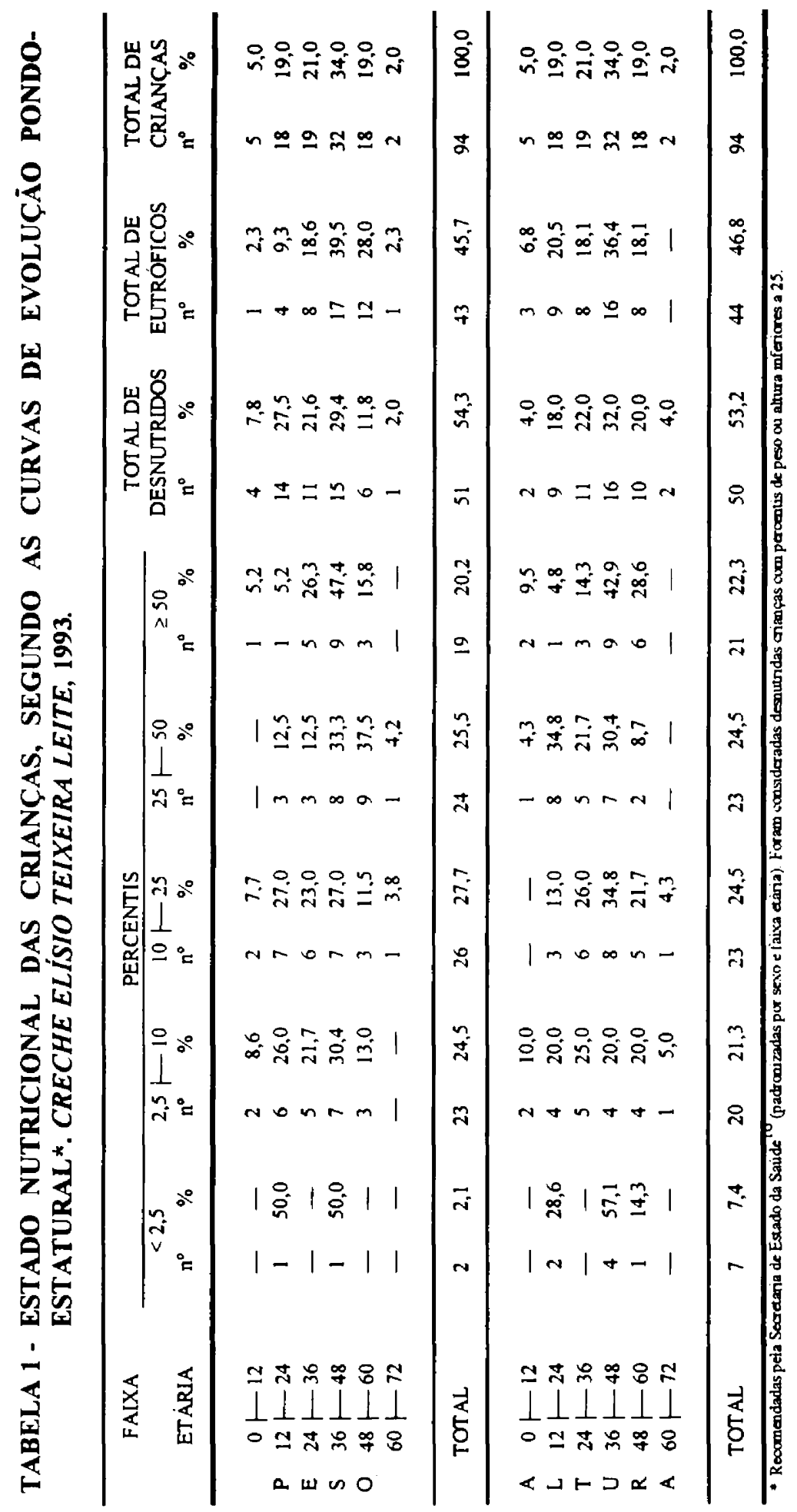




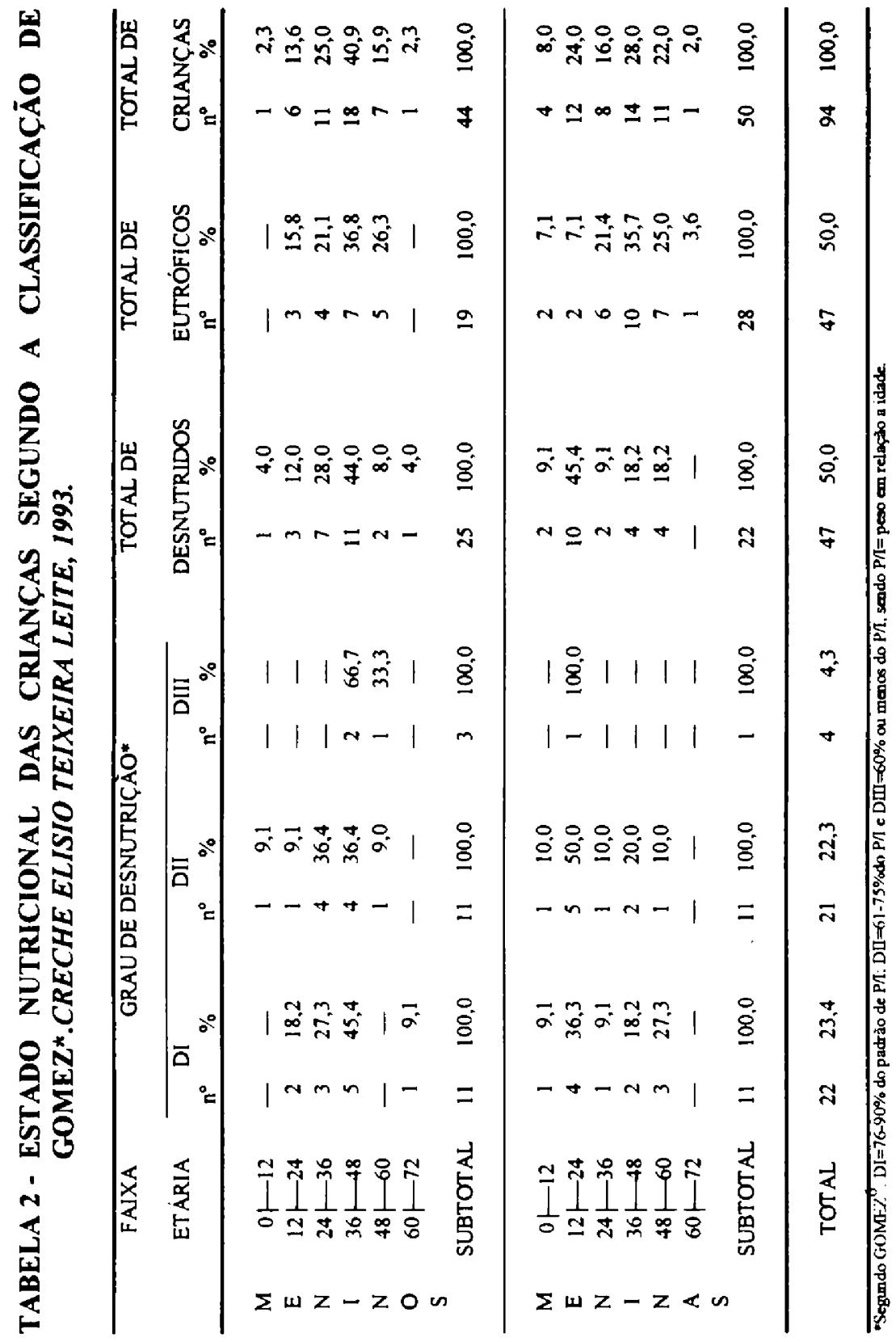


Utilizando os mesmos critérios de Gomez, M(ONTEIRO() encontrou na cidade de São Paulo entre 1984 e 1985, uma prevalência de desnutrição infe. rior, estimada em $25,9 \%$ e presente apenas em formas leves e moderadas. Entretanto, os resultados do presente estudo se aproximam daqueles estima. dos para o Brasil, através da classificação de (Gomez, que mostram uma prevalência de $46,1 \%$ (ENDEF 1974-1975) e 30,7\% (PNSN 1989) para todas as formas de desnutrição ${ }^{27}$. Já, a porcentagem de crianças vítimas das formas mais graves de desnutrição ( $28.6 \%$ com desnutrição moderada e severa) mostra-se superior até mesmo d̀ apresentada para a região Nordeste nestes dois inquéritos ( $21,2 \%$ e $10,1 \%$, respectivamente).

A incidência de desnutrição também por este critério de classificação ('Tabela 2), se concentrou nas faixas de idade correspondentes a 12.48 meses. totalizando $75,5 \%$ das crianças desnutridas. Estes resultados parecem refletir o maior número de crianças matriculadas neste grupo etário, mas se assemelha ao obtido pelo ENDEF $1974-1975^{4}$ que apresentou maior prevalencia de desnutriçāo nesta faixa de idade.

$O$ total de desnutridos $(47.9 \%)$ diagnosticados pela classificação de Waterlow ${ }^{18}$ (Tabela 3), se apresentou ligeiramente menor que o obtido pela classificação de (iomez. sendo também distribuído equitativamente entre meninos e meninas e concentrado na mesma faixa de idade ( 12.48 meses). $\Lambda$ classificação de Waterlow ${ }^{18}$, considera não apenas o "deficit" ponderal em relação à idade, mas inclui o "deficit" estatural e a avaliação do índice pesol altura (P/A). Na amostra estudada. $12,8 \%$ das crianças apresentaram apenas "deficit" estatural, sendo a relação P/A considerada adequada, evidenciando a existência de desnutrição pregressa. Também a PNSN $1989^{5.7}$ constatou que $15,4 \%$ das crianças brasileiras apresentavam-se na condição de "nanismo" (desnutrição pregressa) comprometendo o crescimento esquelético. enquanto apenas $2 \%$ tinham desnutrição aguda. Isto coloca o atraso de crescimento estatural e a desnutrição crônica-pregressa como prevalentes no Brasil ${ }^{2.5}$.

MONTEIR( $)^{9}$ estudando préescolares de baixa renda do Estado de São Paulo estima que o "déficit" de altura ocorreria antes da idade pré-escolar uma vez que, aos 24 meses, $90 \%$ desse "deficit" já estaria estabelecido e se manteria estável. () "déficit" de peso. por sua vez, ocorreria durante a lase pré-escolar e se elevaria progressivamente com o decorrer da idade. A alta incidência de desnutrição crônica atual da creche esludada (\$4.4\% dos des. nutridos e $30,8 \%$ do total da amostra) corrobora estas observações e sugere que as crianças vem mantendo incrementos desfavoráveis de peso e estatura mesmo recebendo as refeiçōes na creche. Este fato parece demonstrar que. mesmo fornecendo todas as refeiçoes, a creche não supre as necessidades gerais de recuperação das crianças. observação que implica em avaliaçóces mais aprofundadas do consumo alimentar e do acompanhamento do crescimento das crianças para uma comprovação efetiva da inadequação. 


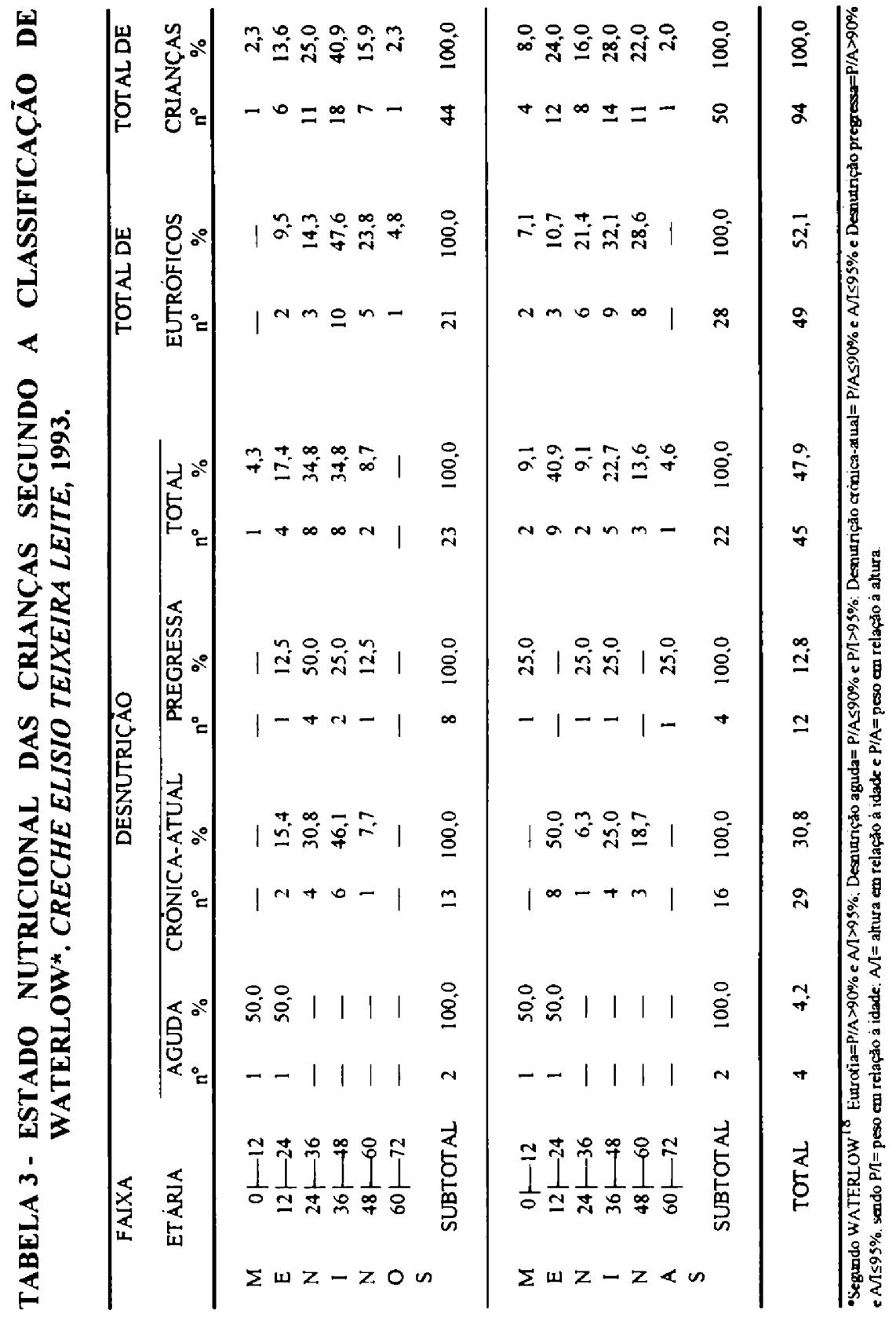


Vale salientar que, mais importante do que comparar a magnitude dos deficits de peso e altura num dado momento, seria avaliar a evolução dos mesmos no decorrer da idade. Esta medida, de caráter obrigatório em instituições que atendem criança, em tempo integral, poderia evitar que o agravo nutricional viesse comprometer globalmente a velocidade de crescimento, determinando que estas crianças cheguem aos 7 anos com "deficits" de aproximadamente $5 \mathrm{~cm}$ na altura e 5 quilos no peso, conforme o encontrado por MONTEIRO ${ }^{9}$. A operacionalização dessa medida, no entanto, implica no levantamento das reais dificuldades para a manutenção da avaliação do crescimento e desenvolvimento na creche, aliada à promoção de educação continuada ou reciclagem dos profissionais envolvidos com a mesma. Além dessa, outras medidas de caráter preventivo, deveriam incluir a ampliação do número de vagas ou mesmo a utilização máxima da capacidade da creche para o módulo de 0-24 meses, não só detectando, mas prevenindo déficits estaturais.

\section{Perfil de morbidade}

As figuras 1, 2 e:3 mostram a incidência das principais doenças (\% episódios) detectadas em meninos e meninas, desde a data de matrícula (janeiro-abril de 1993). ()bservou-se alta incidencia, tanto de doenças intestinais como respiratórias, sobretudo quando consideradas no conjunto de suas diferentes manifestações. De uma forma geral, os meninos se mostraram mais atingidos por gastroenterocolite aguda (GECA), pneumonia e anemias, enquanto as meninas apresentaram maior número de episódios de diarróias e resfriados. Verminoses, vômitos, amigdalites, bronquites e otites distribúram-se homogeneamente entre os dois sexos.

() quadro obtido não difere do perfil de morbi-mortalidade encontrado pela PNSN 1989, onde as doenças infecciosas intestinais e respiratorias aparecem como principais causas de $6 b^{b} \mathrm{t}^{5}$.

\section{Procedência das crianças desnutridas}

Analisando-se a procedência das crianças desnutridas (Tabela 4) observa-se que $63,3 \%$ estão distribuidas nas micro-áreas 4 e 5 , sobretudo as acometidas pelas formas mais graves de desnutrição $(33,3 \%$ de graus II e 111). Já do total das crianças procedentes da micro-area 6 , onde se situa a creche. $23.3 \%$ se apresentam desnutridas (grau I e $\mathrm{Il}$ ).

Assim. os resultados encontrados tambem parecem refletir as condições sócio-econômicas da popu lação das diferentes micro-áreas de abrangência da creche e mesmo do Distrito de Perus-São Paulo. Em geral, nessas microareas, predominam baixos salários aliados as condiçoes inadequadas de habitação. saneamento básico ou seja, precárias condições de vida e existênciali ${ }^{17}$. 


\section{FIGURA 1 - INCIDÊNCIA DE DOENÇAS INTESTINAIS. CRECHE ELISIO TEIXEIRA LEITE, 1993. \\ Doencas intestinais}

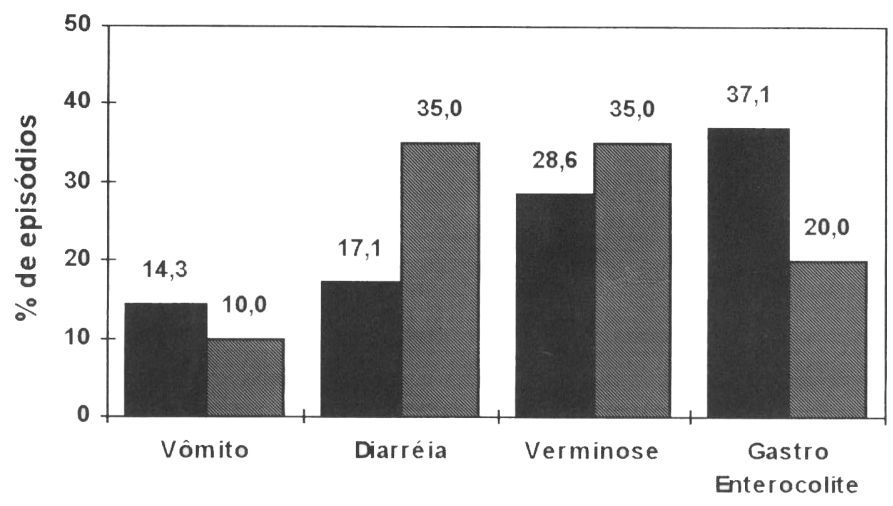

MENNOS MENNAS

FIGURA 2 - INCIDÊNCIA DE DOENÇAS INFECTO-RESPIRATÓRIAS. CRECHE ELISIO TEIXEIRA LEITE, 1993.

Doenças infecto respiratórias

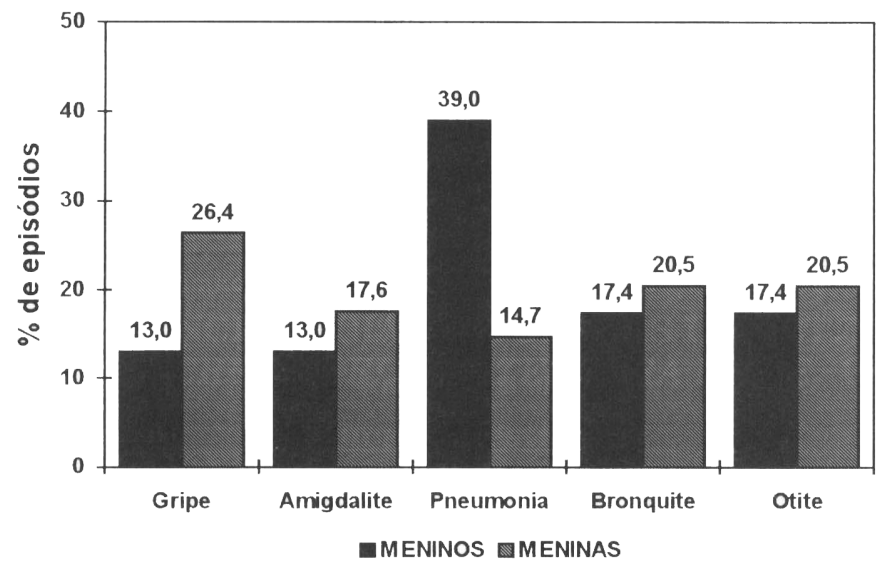




\section{FIGURA 3 - INCIDÊNCIA DE OUTRAS MORBIDADES. CRECHE ELISIO TEIXEIRA, 1993.}

\section{Outras}

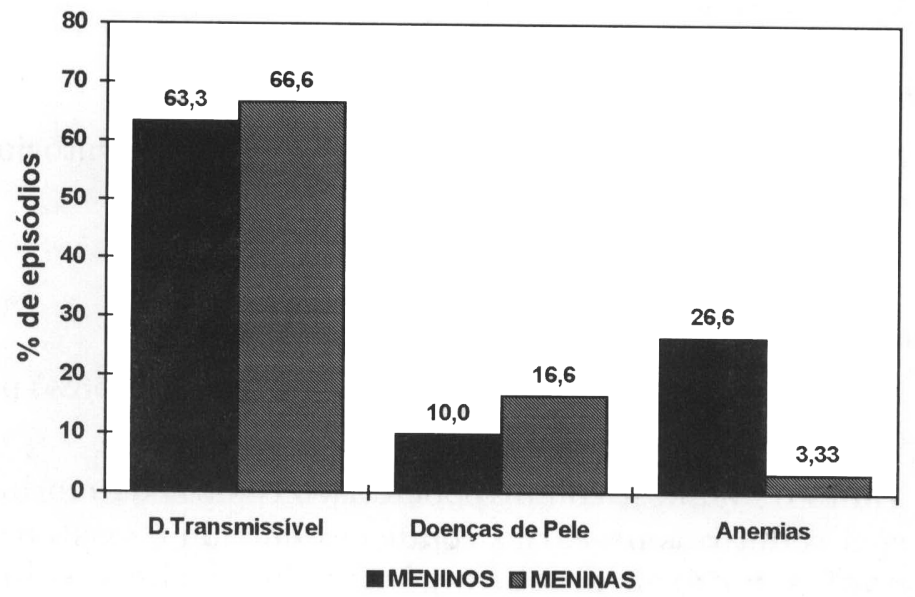

\section{CONCLUSÕES}

Os resultados obtidos evidenciaram:

Quanto ao diagnóstico antropométrico:

- Elevada incidência de desnutrição na creche estudada. A porcentagem de desnutridos obtida através de diferentes criterios diagnósticos foi: $53,2 \%$ pelas curvas de evolução pondo-estatural; $50,0 \%$ pela classificação de Gomez e 47,9\% pela classificação de Waterlow;

- Predominância de formas leves $(23,4 \%)$ e moderadas $(22,3 \%)$ de desnutrição, de acordo com a classificação de Gomez; 
- Maior incidência de desnutrição crônica-atual (30,8\%) de acordo com a classificação de Waterlow, indicando incrementos desfavoráveis de peso e estatura mesmo em crianças que receberam todas as refeiçoes na creche;

- Maior concentração de desnutridos na faixa de $12-48$ meses de idade.

\section{Quanto à incidência das principais morbidades:}

- Maior ocorrência de doenças intestinais e respiratórias, sobretudo em meninos.

\section{Quanto à procedência das crianças desnutridas:}

- Maior porcentagem de crianças desnutridas (63.3\%) procedentes das microáreas 4 e 5.

- Tanto o diagnóstico antropométrico como o de morbidade pareeem refletir as precárias condições de vida e existência predomi nantes na area de abrangência da crecho o sobretudo nas microáreas de procedência das crianças desnutridas.

BERTHO, M.P.et al Disease and nutritional diagnostic of institutionalized children. Daycare center Elísio Teixeira Leite, Perus. SP. 1993. Rev. Esc. Knf.USP. v.29. n.2. p.141-57. aug. 1995

As a part of one survey about health conditions in institutionalized children, the nutritional status were evaluated. Data were obtained through antropometric assessment in a sample of 111 pre-school children matriculated in a small official day-care center in Perus - SP. According to Gomez, 50,0\% of all that children were classified as malnourished, $23,4 \%$ of then in the I degree; $22,4 \%$ in II degree and only 4,3\% in III degree. Taking into account the Waterlow's classification there was a highest frequency of cronic-actual malnutrition $(30,8 \%)$ concentrated in children between 12-48 months of age. Additionally, these children presented highest incidence of infective - respiratory and intestinal diseases. These evidences lead on to the improvement of the follow-up of children growth and food consumption, specially of that under 24 meses, to attempt for an early identification of malnutrition. thus increasing the chance of nutritional recuperation.

INITERMS: Children health. Antrophometric diagnostic Pre-school children. 


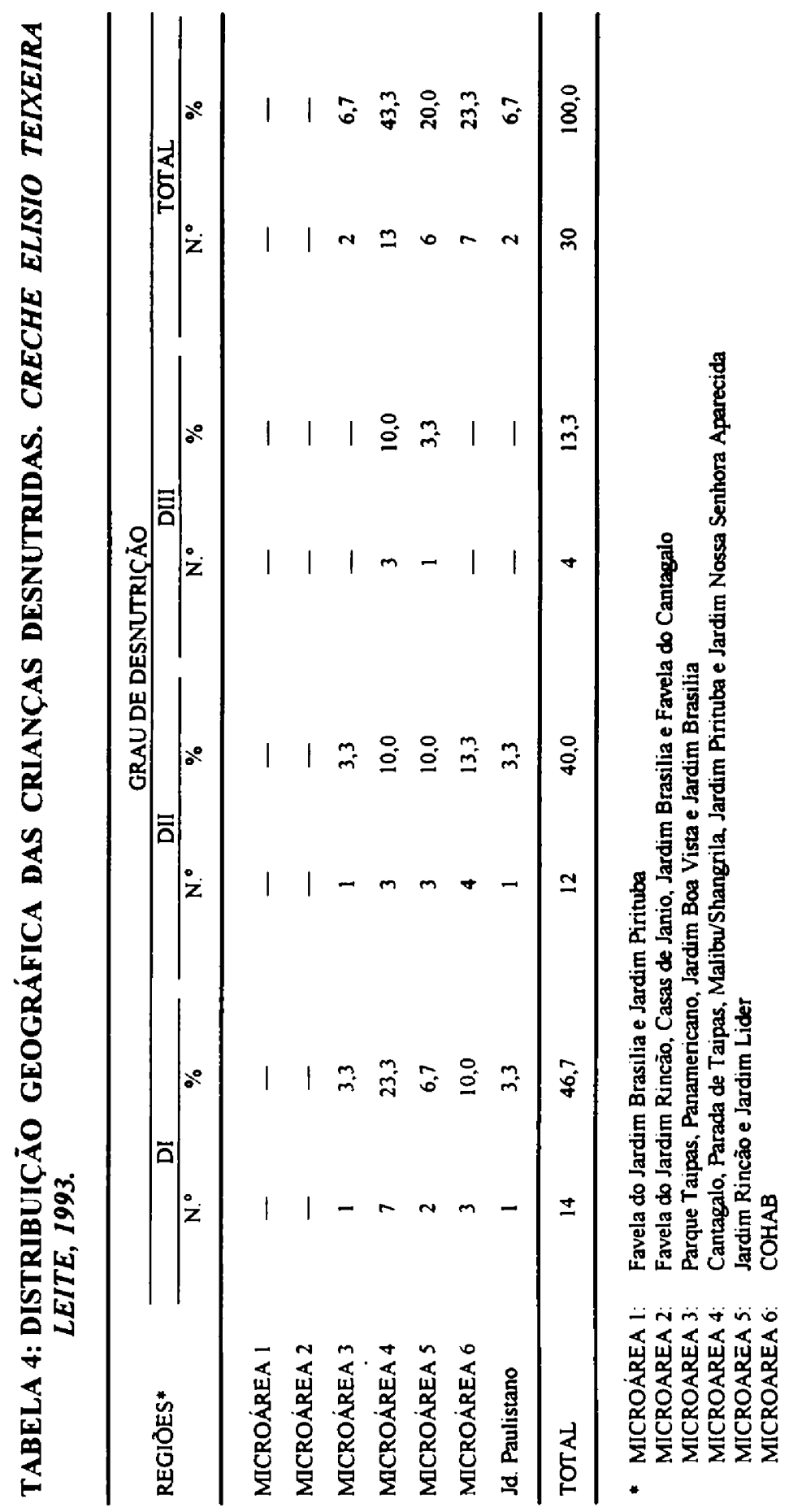




\section{REFERÊNCIAS BIBLIOGRÁFICAS}

1. BARELLI. W. Perfil do consumo alimentar da classe trabalhadora. Saúde Deb., v.23. p.2657. 1988

2. BATISTA FILHO. M. FERNANDES. M.F. Situação nutricional da criança no Brasil. Bol. Nac.SISVAN. v.1.p.12-4, 1991

3. CAR VALHO. A. As distorçoes nos programas alimentares em curso e propostas de medidas racionalizadoras. Cad NESP, v.2. p.49-51. 1988

4. FUNDAÇÃO INSTITUTO BRASILEIRO DE GEOGRAFIA E ESTATÍSTICA/FUNDO DAS NA NAÇÕES UNIDAS PARA A INFÂNCIA/INSTITUTO NACIONAL DE ALIMENTA. ÇÃO E NUTRIÇÃO. Perfil estatístico de crianças e maes no Brasilia aspéctos de salide e nutriçáo de crianças no Brasil. 1989. Rio de Janeiro. 1992.

5. FUNDAÇÃO INSTITUTO BRASILEIRO DE GEOGRAFIA E ESTATÍSTICA/FUNDO DAS NA NAÇŌES UNIDAS PARA A INFÂNCIA Crianças e adolescentes: indicadores sociais. Rio de Janeiro. 1992. v.4.

6. GOMEZ. F. et al. Mortality in second and third degree malnutrition J.Trop.Pediatr. v.2 p. 77.83 .1956$.

7. INSTITUTO NACIONAL DE ALIMENTAÇÃO E NUTRIÇÃO/FUNDAÇÃO INSTITUTO BRASILEIRO DE GEOGRAFIA E ESTATÍSTICA/NSTITUTO DE PESQUISA EM ECONOMIA AGRICOLA Pesquisa nacional sobre saúde e nutriça: resultados prelimi. nares. Rio de Janeiro, 1990.

8. MARQUES. R.M et al Crescimento e desenvolvimento pubertário em crianças e adolescentes brasileiros II: altura e peso. Sao Paulo. Brasileira de Ciências. 1982

9. MONTEIRO. C.A. et al. Estudo antropométrico de pré.escolares de áreas de baixa renda do Estado de Så Paulo. Brasil Rev.Saúde Públ. v. 18. n.1.p.1-18. 1984.

10. MONTEIRO. C.A et al. Estudo das condiçoes de saúde das crianças do Município de Sao Paulo 1984-1985: Aspectos métodológicos. características sócio-econômicas e ambiente físico. Rev.Saúde Públ v.20. n.6. p.435.45 1986

11. MONTEIRO. C.A et al. Estudo das condiçoes de saúde das crianças do município de São Paulo 1984-1985: II antropometria nutricional Rev Saúde Públ. v.20.n.6. p.446-53. 1986 .

12. MONTEIRO. C.A Saúde e nutrigato de crianças de São Paulo. Săo Paulo. Hucitec, 1988

13. OLIVEIRA. Z M.R. FERREIRA, M. C R. Propostas para o atendimento em creches no municipio de São Paulo Cad Pesq. v.56. p. 39-65. 1986.

14. PELIANO. A M T M. Breve retrospectiva histórica. Cad NESP. v.2, p.42-7. 1988

15. PELIANO A.M.T.M. Os programas de alimentação e nutrição para mães e crianças no Brasil. In: FUNDAÇÃO INSTITUTO BRASILEIRO DE GEOGRAFIA E ESTATÍSTICA/ FUNDO DAS NAÇÓES UNIDAS PARA A INFÂNCIA/INSTITUTO NACIONAL DE ALIMENTAÇĀO E NUTRIÇĀO. Perfil estatístico de crianças e mães no Brasil: aspectos 
16. SAO PAULO (Estado). Leis etc. Norma Técnica SS n".33/85. Critérios para inscriçăo e acompanhamento na atividade de recuperaçáo nutricional. Diário Oficial do Estado. Sáo Paulo, 22 de março de 1985. p.1.6.

17. SEADE - São Paulo. Pobreza e riqueza: pesquisa de condiçoes de vida na regiáo metropoli. tana de Sao Paulo - uma amostragem multifatorial, 1992

17. WATERLOW. L.C. Classification and definition of protein energy malnutrition. In: BEATON,

G.H. BENGOA. J. Nutrition in preventive medicine. Geneva. World Health Organization. 1976. annex 5.p.530-55.

18. WILSON. D. etal. Nutritional status of children inmates of a small institution for homeless children in the capital of the state of Så Paulo, Brazil. Rev.Saúde Públ., v. 14, n. 3, p.300-9. 1980 . 